Printed in Great Britain

\title{
THE FEEDING BEHAVIOUR OF STARFISH ON ESSEX OYSTER BEDS
}

\author{
By D. A. Hancock \\ Fisheries Laboratory, Burnham-on-Crouch, Essex
}

(Plate I and Text-figs. I-3)

\section{STARFISH ON OYSTER BEDS}

Two species of starfish are found in large numbers in Essex rivers. They are Asterias rubens $\mathrm{L}$. and the common sunstar Solaster papposus (L.). Of these, Asterias rubens has been regarded for many years as a voracious predator of oysters. Forbes (I84I) recorded that it preyed on all kinds of Mollusca, and was commonly found with Natica in its stomach. He quotes Bishop Sprat's History of the Royal Society, in which the Admiralty Court laid penalties on those engaged in the oyster fishery 'who do not tread under their feet, or throw upon the shore, a fish which they call Five-finger, resembling a spurrowel, because that fish gets into the oysters when they gape and sucks them out'. Of Solaster papposus he said: 'It is very ravenous, devouring shellfish. It frequents oyster and scallop banks, often in great numbers, and sometimes colonizes the sides of harbours frequented by oyster dredgers, in company with Uraster rubens.'

It has been readily confirmed since Forbes's time that Asterias rubens will feed on oysters, and it has been said to do so with such frequency as to cause very serious depredations. Cuénot (I887) recorded that a natural oyster bed of IO-I2 km length had been completely destroyed by starfish, introduced incidentally by fishermen in their nets.

In Canada and the United States starfish present the oystermen with a severe problem. Needler (I94I) regarded the starfish (A. vulgaris) as the worst enemy of oysters in Canadian Atlantic waters and one of the more serious obstacles to successful oyster farming. Galtsoff \& Loosanoff (1939) stated that since the beginning of oyster culture in the United States in I845, the starfish $(A$. forbesi) has been regarded as one of the most destructive enemies of shellfish on the Atlantic coast, and that by far the greater part of the loss caused is borne by the oyster growers. One estimate is that since I92I no less than 500,000 bushels of oysters have been destroyed every year, representing an annual loss of 500,000 dollars. The decline in the scallop industry in Buzzards Bay was also attributed to the depredations of the starfish (Galtsoff \& Loosanoff, I939).

Korringa (195I) found that although A. rubens occurs on the Dutch oyster beds, the number of adult oysters devoured gives no cause for serious anxiety, 
because the starfish apparently prefer mussels, or encounter less difficulty in opening them. Serious damage may, however, be caused by young starfishes among the tiny oyster spat on the tile-collectors.

In this country the starfish $A$. rubens has always been regarded by fishermen as the traditional enemy of mussels and oysters. Laver (I9I6) listed the starfish or 'Five-finger' as the most injurious of the direct enemies of the oyster in the Colchester Oyster Fishery. Collard (1902) referred to the starfish as a deadly foe of the Whitstable oyster.

Large numbers of $A$. rubens appear from time to time on oyster grounds in the River Crouch. They are numerous outside the mouth of the river, and particularly off the coast of Whitstable, where for many years the collection of starfish for fertilizer has been a substantial fishery.

Oystermen in the United States undertake costly control measures, usually with boats equipped with starfish mops. Lee (I95I) estimated that the direct cost of control efforts amounts to more than 500,000 dollars annually. Scientists in the United States and Canada have enjoyed considerable success with the use of quicklime as a means of control (Galtsoff \& Loosanoff, I939; Loosanoff \& Engle, I942; Lee, I95I). Particles of quicklime spread over the oyster beds quickly sink to the bottom, and on to the surface membrane of the starfish. The caustic action of slaking lime causes lesions which penetrate and spread, eventually causing the death of the starfish. Its effects on oysters and other commercial species are considered to be negligible.

In Holland, the use of a spiked roller for catching starfish has been tried, but abandoned (Lambert, I95I), because of damage to the oysters. Copper sulphate and lime were found to be effective experimentally as methods of chemical control, but dredging is still the only means of destruction generally employed.

In this country, starfish are removed from the dredges during routine oyster cultivation and killed by drying out.

The work forming the subject of this paper was undertaken to test the efficiency of measures of chemical control of native starfish, and to decide whether more intensive control measures could be justified.

\section{THE Food of Starfish}

Hunt (1925) examined the stomach contents of $A$. rubens from the Plymouth fishing grounds but found that only a small percentage contained recognizable remains. He rightly concluded that this was a result of their feeding method. The mouth of the starfish is small, and digestion of larger animals is largely external. He however recorded the feeding of Asterias on small specimens of the molluscs Venus, Dosinia, Mactra, Pecten, Corbula, Cultellus, Lutraria, Syndosmya and Turritella, and found the remains of the crustaceans Portunus, Diastylis and Balanus and the polychaete Flabelligera. In Solaster papposus he 
found occasional remains of Asterias rubens and a small Pecten, but was unable to induce Solaster to feed under laboratory conditions. Blegvad (I9I4) had previously recorded that Asterias is devoured by larger individuals of its own kind and by Solaster. According to Mortensen (1927) the food of Asterias consists principally of molluscs, but it also eats crustaceans (especially barnacles), worms, echinoderms, even specimens of its own species, indeed almost everything eatable, living or dead. He said that it does considerable damage to oyster cultures, though it would appear that it cannot, by itself, open the large, undamaged oysters. It is itself eaten only by other sea-stars (Solaster, Luidia ciliaris). Vevers (I949) stated that while still in a young stage Asterias rubens eats barnacles and small lamellibranchs, but as an adult it feeds chiefly on worms, crustaceans, other echinoderms and many lamellibranchs, in particular Chlamys opercularis (L) and Mytilus edulis. In fact it would appear to be omnivorous, eating any living or dead material on which it can get a firm hold. Bull (I934) made some aquarium observations and found that Solaster papposus, S. endeca and the northern stone crab, Lithodes maia, fed in captivity mainly on Asterias rubens. Solaster also ate numbers of Metridium senile but would feed on molluscs or mollusc flesh only under conditions of extreme starvation.

The smallness of the mouth aperture in both Asterias and Solaster limits the size of prey which can be taken into the stomach in a recognizable form. The mouth aperture of Solaster is, however, larger than that of Asterias, a Solaster of $85 \mathrm{~mm}$ maximum radius having an aperture of $\mathrm{I} 7 \mathrm{~mm}$ diameter, compared with only $4 \mathrm{~mm}$ for the mouth of an Asterias of similar size. For this reason recognizable stomach contents are more likely to be found in Solaster, but they still represent only the smaller items of its diet. Although the stomach contents of many starfish trawled in the Irish Sea were examined by the author, no Asterias and only two Solaster contained recognizable remains. Of these, one, of $75 \mathrm{~mm}$ maximum radius, contained a small Chlamys valve, a Turritella shell and several pieces of Asterias arm. The second, of $80 \mathrm{~mm}$ radius, contained a number of spines which were identical with those of Psammechinus taken in the same trawl.

In order to determine the larger food eaten by starfish they must be taken in the field when actually feeding, or observed feeding in aquarium tanks. During the course of dredging in the River Crouch, Essex, it has been established that the largest numbers of Asterias rubens are found on and in the neighbourhood of the Southward Laying, I mile below Burnham-on-Crouch (Text-fig. 2). Closely associated with it, but in less abundance, is Solaster papposus, and almost always in the same dredge are found several stone crabs, Hyas araneus. Subsequent dredging in the Rivers Crouch and Colne have confirmed that these three species are usually found together. Asterias taken from the dredges are frequently found in a characteristic arched feeding position but usually the prey has been released. Occasionally the prey is 
retained and has been recorded. Asterias from the River Crouch have been observed feeding on oysters, slipper limpets (Crepidula fornicata), barnacles, Spisula and Littorina. Solaster has frequently been taken with the arms of Asterias in its stomach, and also quite often with pieces of Alcyonidium gelatinosum, which is abundant in this river. One small Gibbula and a small individual of Crepidula have also been found in the stomach of Solaster in the field.

The bottom community from which the Asterias is taken gives a good guide to the type of food which is being eaten. Asterias have frequently been recorded in large numbers on mussel beds off the Kent coast, and outside the mouth of the River Crouch, with obvious evidence of their depredations. Korringa (I95I) records that Dutch oystermen occasionally see great numbers of the starfish Asterias rubens floating on the surface by means of gas bubbles. They believe that this is a method of migrating to other feeding grounds. In Britain this belief is also held locally, particularly at Whitstable, where the phenomenon is said to be associated with the destruction of one mussel bed and the search for another. It is agreed with Korringa that there is no scientific evidence to support this observation: it may be of abnormal occurrence, or due to pathological conditions, but the reports of local fishermen are seldom without foundation. In the River Crouch, particularly on the Southward Laying, where enormous numbers of Crepidula occur farther offshore than the main concentrations of oysters, the Asterias were found to be associated with the Crepidula, and were found in the dredges to be feeding on it. During 2 weeks in February and March, more than 10,000 Asterias were removed by the Ministry's two vessels from the offshore part of the Southward Laying, where the fauna consists almost entirely of Crepidula with some barnacles. In the mouth of the River Colne recent changes in conditions have led to the almost complete disappearance of oysters. Crepidula are abundant there in places, and also Asterias, which are often taken in the dredges feeding on Crepidula. Mr Francis, foreman of the Colne Fishery Board, was so convinced that the Asterias were substantially reducing the population of Crepidula, that, contrary to normal practice the starfish were returned to the ground to continue their good work.

Confirmation of the feeding behaviour suggested by field observations was sought in laboratory experiments. First, it was demonstrated that quicklime, sprinkled over the surface of the water in porcelain sinks containing Asterias, caused severe burns and lesions on the starfish, followed by their disintegration and death within about 3 days. Attention was then directed towards the advisability of using such drastic control measures on the oyster beds. It was decided that a series of laboratory experiments would help to assess the magnitude of the predations of starfish on the oysters. 


\section{LABORATORY OBSERVATIONS}

During the course of the experiments a large stock tank containing various shellfish and starfish was maintained, and provided a series of interesting observations. The tank contained a population of mixed sizes of Asterias rubens with several Solaster papposus and Hyas araneus, and an abundance of oysters and oyster spat, barnacles, Urosalpinx and Crepidula. During the period II-27 January 1954, although many Crepidula and some Urosalpinx and barnacles had been devoured, only one small oyster and no oyster spat had been eaten. Between 17 March and 21 April 1954, a total of 262 Crepidula, and 28 Urosalpinx were devoured compared with only two brood oysters and no oyster spat. No count was kept of barnacles eaten. On one occasion, the introduction of a quantity of fresh Crepidula chains into the corner of the stock tank was followed almost immediately by the migration of thirteen out of twenty of the Asterias to that corner and extensive feeding.

Other shellfish devoured by Asterias in this stock tank included several Pecten maximus and Mya arenaria. One Asterias was observed attacking and devouring a smaller individual of the same species.

During the course of these observations Solaster was once observed feeding on a brood oyster, and very occasionally on a Crepidula chain. It was frequently observed to attack Asterias, individual arms of which were often taken from the stomach of Solaster.

Asterias, but rarely Solaster, was frequently attacked by Hyas (see 'Method of feeding' p. 32I), which injures the arms by constricting them with its chelae, and biting the tips with its mandibles. A check on the Asterias in the tank showed that six Solaster and six Hyas had between them accounted for several complete Asterias, between one and three arms from each of nine others, and the tips or ends of arms from eight others during a period of 2 weeks in March. The Solaster had only rarely been damaged.

Several shore crabs, Carcinas maenas, which are found in the dredges with Hyas, were introduced into the tank, but on no occasion were they suspected of attacking starfish.

Further experiments were designed to discover the type of food on which Asterias and Solaster will feed. These were followed by offering Asterias various foods in equal quantity, in order to determine those which are the most important in its diet.

\section{Experiment I}

This was designed to estimate the rate of destruction of brood oysters in the absence of other food.

Four large Asterias (maximum radius $\mathrm{I} 40 \mathrm{~mm}$ ) were placed in a large tank containing sixteen adult oysters. As each oyster was consumed it was removed, and replaced by another of approximately the same size. It was found that 
the Asterias assumed a feeding position in less than 2 days, and within 3 days of commencing the experiment two oysters had been consumed. During the period 7 January-2I April 1954, the four starfish consumed an average of 4.8 oysters per week. The largest number of oysters eaten in I week was eight. The oysters used were between 44 and $76 \mathrm{~mm}$ average diameter. One Asterias ( $\left.\sigma^{7}\right)$ spawned on II May at a temperature of $15.3^{\circ} \mathrm{C}$. Two others spawned on 29 May. Feeding stopped a few days before and after spawning and did not resume its former intensity throughout the summer. Generally an oyster was opened and consumed in less than 2 days. One starfish was observed to complete the process in $22 \mathrm{~h}$ during March, and a period of less than $24 \mathrm{~h}$ was recorded on several occasions. Evidently the larger starfish can and will eat oysters consistently in the absence of other food, and their rate of feeding under such conditions would constitute a serious menace to oyster growers.

\section{Experiment 2}

This was designed to discover on which other animals the starfish will feed, in the presence of oysters. Four Asterias ranging from 50 to $120 \mathrm{~mm}$ maximum radius of arm, were confined with abundant food including oysters, oyster spat, Mytilus, Cardium, Paphia, Macoma, Buccinum, Crepidula, Nassarius, Nucella, Urosalpinx, Littorina, Gibbula and barnacles. It was not possible to keep equal numbers of each food throughout the experiment or to replace each one immediately it was consumed, but a stock of 6 oysters and 6 shells bearing oyster spat (17) was maintained, and at no time did the total of any other species exceed this figure. From 4 January to 24 March 1954, the 4 Asterias consumed 45 Mytilus, I2 Macoma, Io Cardium, 4 Urosalpinx, 4 Nucella, 3 Paphia, 3 Crepidula, I Nassarius, I Littorina and I Gibbula. It is significant that during this time no oysters or oyster spat were consumed. It was concluded that barnacles provided little attraction because many of the food animals devoured were coated with undamaged barnacles, mainly Elminius.

\section{Experiment 3}

Four Solaster (55-70 mm maximum radius) were confined with abundant food supply including oysters, oyster spat, Mytilus, Cardium, Littorina, Urosalpinx, Crepidula, Macoma, Metridium and I Psammechinus, but no Asterias. From 5 January to II March, only 3 Cardium, 2 Macoma, I Psammechinus, I oyster spat and I Metridium were devoured. It has been found that the feeding rate of starfish decreases before and during spawning. The Solaster spawned in the sink on 25 February, but this low rate of feeding could not entirely be associated with this fact, but was almost certainly due to an unsuitable food supply. When, on I2 March, an Asterias was added it was rapidly devoured, the remains being found in the stomachs of 3 Solaster. 
When further Asterias were added they were attacked almost at once by the Solaster. Evidently Solaster can eat other food, but its natural food certainly includes Asterias, confirming the observations made in the field.

\section{Experiment 4}

The preliminary experiments seemed to indicate that Mytilus provides the greatest attraction to Asterias, but the number of mussels occurring at the Southward Laying (Mistakidis, I95I, and own observations), and generally in the River Crouch, is insignificant compared with other organisms. For this reason, only the more important animals related to oyster cultivation were included as food in this experiment. Four Asterias (maximum radius $60-120 \mathrm{~mm}$ ) were confined with 6 brood oysters, 6 chains of Crepidula, 6 oyster shells each bearing several oyster spat, and 6 Urosalpinx. Between 25 March and 22 June, I brood oyster, 8 oyster spat, 27 Crepidula and Io Urosalpinx were devoured.

\section{Experiment 5}

During the field observations mentioned previously, it was found that Asterias is frequently found feeding on Crepidula. In order to determine to what extent Asterias will feed on Crepidula in the presence of oysters, Io Asterias (maximum radius $70-108 \mathrm{~mm}$ ) were confined with 20 Crepidula chains and 20 small oysters, the largest oyster measuring $54 \mathrm{~mm}$ average diameter. These were distributed at random in a large tank with running sea water. After 5 days (20-25 March 1954) it was found that every Crepidula chain had been attacked to some extent, with as many as five individuals eaten from one chain. A total of 53 individuals of Crepidula, most of them adult, were eaten. This must be compared with the consumption of only 3 oysters. In a subsequent experiment the same ro Asterias were used and 20 adult individuals of Crepidula were distributed at random with 20 oysters. During a period of $\mathrm{I}_{4}$ days (25 March-8 April) 9 oysters and I3 Crepidula were eaten. The possible explanations of the lower proportion of Crepidula eaten are believed to be first, that a chain of individuals exerts a greater attraction than a single one, or, secondly, that, attraction being discounted, the random movements of the starfish were interrupted by the presence in one place of a series of readily accessible animals provided by a chain. It must be remembered, however, that in the first part of this experiment all 20 of the chains had been attacked by Asterias, and that under natural conditions there is an ample supply of Crepidula which are more likely than not to be concentrated in chains. In a subsequent experiment 20 oysters were placed in one corner of the tank (area $160 \mathrm{~cm}$ square) and 20 chains of Crepidula in the opposite corner, with Io Asterias in the centre of the tank. In 6 days (8-I4 April), 4 oysters and 33 Crepidula were eaten. The experiment was repeated, reversing the positions of Crepidula and oysters. In the subsequent 6 days, 4 oysters and 25 Crepidula 
were consumed. This behaviour confirms the suggestion that Asterias prefers Crepidula, possibly because it is less inaccessible than the oyster.

\section{Experiment 6}

It became evident from observations made in the stock tank and subsequent experiments that there was a difference in feeding behaviour according to the size of the starfish. A population of Asterias was divided arbitrarily into sizegroups by reference to a histogram composed from measurements of Asterias dredged from the River Crouch (Text-fig. I). The groups selected weregroup I: <30 mm; group II: 40-70 $\mathrm{mm}$; group III: 70-100 mm; group IV: $>$ I00 $\mathrm{mm}$ maximum radius.

Group I. 23 Asterias of maximum radius $30 \mathrm{~mm}$ were confined with shells and stones bearing oyster spat, Crepidula spat and barnacles, and 6 Urosalpinx. The tanks were examined every day or two and the food eaten was replaced. During the period 22 April-Io May I954, a total of I 5 oyster spat, I3 Crepidula spat and 6000 barnacles, mainly Elminius, had been devoured. These results were consistent throughout the experiment and it was significant that on several occasions an oyster shell was cleared of barnacles leaving several undamaged oyster spat. Further, it was found that the number of oyster spat devoured was always greatest when virtually all the barnacles had been devoured.

Group II. Io Asterias of maximum radius $40-70 \mathrm{~mm}$ were confined with 6 young oysters, 6 shells bearing oyster and Crepidula spat, 6 chains of Crepidula, 6 Urosalpinx and 2 stones covered by barnacles. During the period 22 April-Io May I954, a total of I oyster spat, 2 Crepidula spat and 3500 barnacles were consumed. Although no selection was made of barnacles used in the experiments, those eaten by group II were mainly of a larger size than those eaten by group I, and it was found that the larger barnacles were eaten before the smaller sizes were attacked.

Group III. 7 Asterias of maximum radius 70-100 $\mathrm{mm}$ were confined with 6 young oysters, 6 shells bearing oyster and Crepidula spat and barnacles, 6 chains of Crepidula, 6 Urosalpinx and 2 stones covered by barnacles. Between 22 April and Io May I954, a total of 3 oyster spat, I3 Crepidula spat, 2 oysters, 47 adult Crepidula, I Urosalpinx and 425 barnacles were devoured.

Group IV. 5 Asterias of maximum radius I00-I $45 \mathrm{~mm}$ were confined with unlimited quantities of oysters and oyster spat, Crepidula and its spat, Urosalpinx and barnacle covered shells and stones. During the period 22 April to I4 May I954, a total of I oyster, 29 adult Crepidula and 20 barnacles together with I Pecten maximus, which was being stored in the same tank, were eaten. This confirms the previous result (Exp. 2) that the barnacles provide little attraction for the larger starfish.

In Table I, a comparison is made of the average numbers of different foods eaten by one Asterias from each group in 18 days. It can be seen that the 
smaller sizes of Asterias ate mainly barnacles, with only occasional oyster or Crepidula spat. The larger sizes took fewer barnacles, and ate significantly more Crepidula and its spat than oysters and oyster spat.

It can be seen by reference to the histogram composed from measurements of Asterias dredged from the River Crouch on Io May (Text-fig. I) that groups II and III formed the most substantial proportion of the starfish population. The largest proportion of starfish dredged from the Southward Laying (Text-fig. I) was in group II. The starfish in this histogram are representative of the total population at the Southward Laying, since all parts of the oyster ground were sampled by dredge. Using the histogram and the results shown in Table I, the numbers of oysters and their competitors which would have been eaten by the 95 starfish during 18 days in April-May have been calculated as: 24 oyster spat, 54 Crepidula spat, 5 oysters, II4 Crepidula, 2 Urosalpinx and 26,900 barnacles. This gives a clearer picture of the proportions of food organisms which could be expected to be devoured by the natural starfish population of the Southward Laying under experimental conditions.

\section{Method of FeEdiNG}

Little new information is added here on the actual means by which Asterias and Solaster open the shells of their molluscan prey. The starfish wraps its arms round its prey, attaches itself by the series of tube feet, and proceeds to pull the valves apart. Once opened, the stomach of the starfish is extruded (P1. I, fig. I) into the prey and digestion commences. Extrusion of the stomach is brought about by contraction of the oral and aboral surfaces of the animal which forces coelomic fluid into loose separate folds of the cardiac stomach (Cuénot, I887). Irving (I924) worked out the ciliary currents in the starfish Patiria, and decided that digestion products are distributed by ciliary action, the Tiedemann's diverticulum being a region specialized for distribution.

The mechanics of the process by which the prey is opened have provided a subject for controversy for many years. Schiemenz (1895) explored most possibilities and concluded that a starfish can develop sufficient force to open a bivalve unaided by any poisonous secretion. Van der Heyde (I922) established the presence of a toxic substance in the stomach extract of the starfish Asterias forbesi, using the heart of Pecten and the gastrocnemius muscle of a frog. Sawano \& Mitsugi (1932) found that the stomach extract of Asterias rollestoni caused a tetanic contraction in the heart of the oyster. Cahn (I950) has described the feeding process in the Japanese starfish (A. amurensis), which begins its attack on the oyster by pouring a poison secreted by its stomach into the water in front of the oyster's inhalant siphon. The poison in the inhalant current of water stimulates the oyster to close its shell. The adductor muscle loses tonus and relaxes, and the valves are pulled apart by 

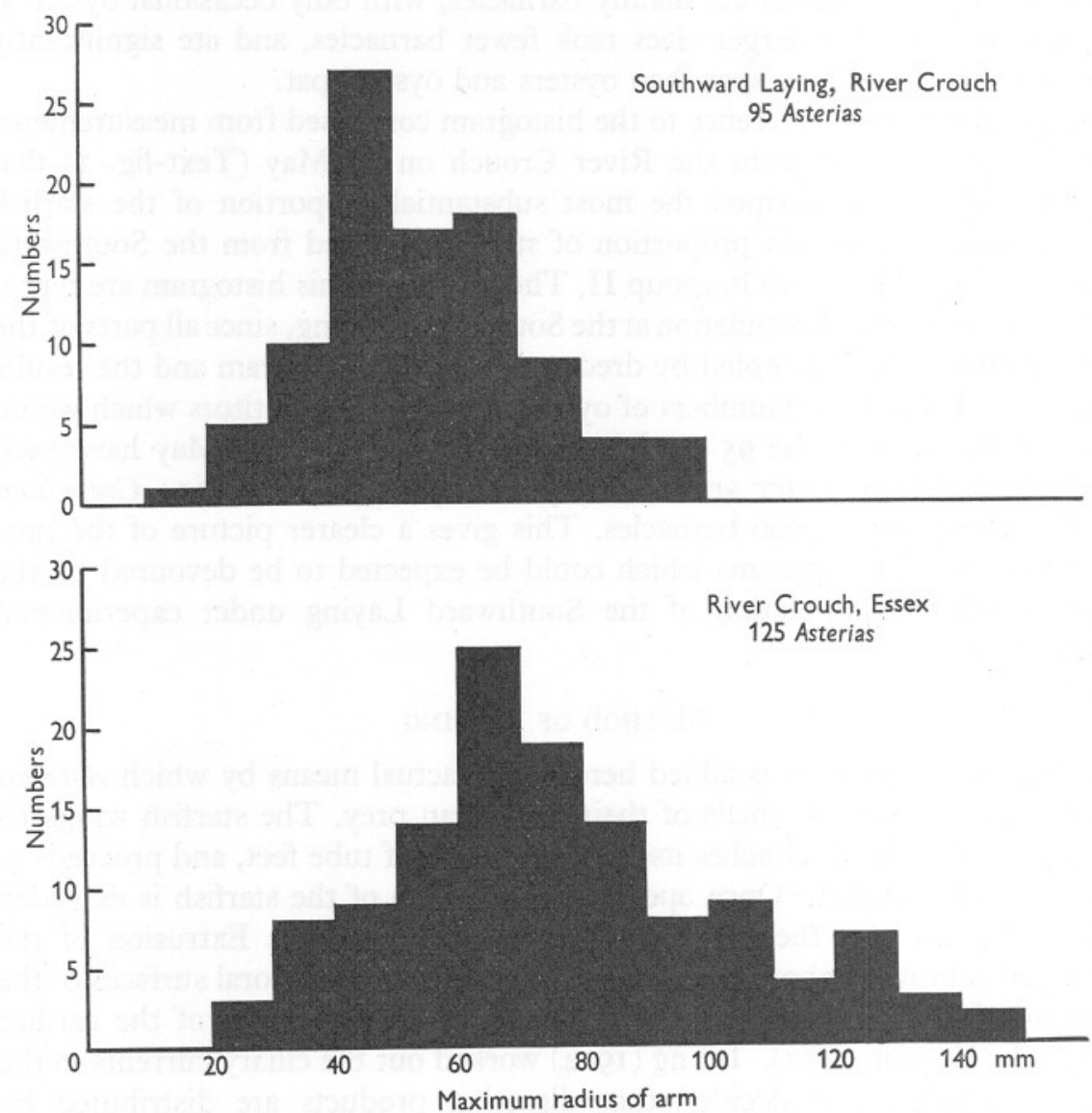

Text-fig. I. Population histograms of Asterias rubens from a dredge survey on Io May 1954.

Table I. Shellfish Devoured by Asterias during the inclusive Period 23 April-Io MAY 1954

Figures reduced to I Asterias in each size group

$\begin{array}{lccccc}\quad \text { Size group } & \ldots & \text { I } & \text { II } & \text { III } & \text { IV } \\ \text { ax. radius (mm) } & \ldots & \text { I5-30 } & 40-70 & 70-\text { I00 } & \text { I0O-I45 } \\ \text { Oyster spat } & & 0 \cdot 7 & 0 \cdot 1 & 0 \cdot 4 & 0 \\ \text { Crepidula } \text { spat } & & 0 \cdot 6 & 0 \cdot 2 & \mathrm{O} \cdot 9 & 0 \\ \text { Oysters } & & 0 & 0 & 0 \cdot 3 & 0 \cdot 2 \\ \text { Crepidula } & & 0 & 0 & 6 \cdot 7 & 4 \cdot 7 \\ \text { Urosalpinx } & & 0 & 0 & 0 \cdot \mathrm{I} & 0 \\ \text { Barnacles } & & 260 & 350 & 6 \mathrm{I} & 3\end{array}$


the tube feet of the starfish. The time required to destroy an oyster is about $2 \mathrm{~h}$ from the first injection of the poison into the water to the complete digestion of the body. Experimentally, this paralysis remains effective for many hours, if it does not result in death.

Even if such an effect could be produced by the stomach extract of $A$. rubens, this explanation is still open to Schiemenz's criticism that a bivalve which has been opened but not digested will quickly recover. With oysters, mussels and Pecten, the author has observed on several occasions that the disengaging of the arms of the starfish has resulted in such rapid closure by the bivalve that the stomach of the starfish was trapped and torn. Evidently if $A$. rubens is able to produce a poison, it can only have a temporary effect and appears not to be lethal.

It is interesting that the outer margin of the oyster shell is invariably broken away during an attack by Asterias, but in other bivalves and Crepidula the shell margin remains intact. This could be said to result from a deliberate chipping away of the edge, which could allow the entry of a narcotic, but is more likely to be due to a strong pull by the starfish which causes the weakest part of the shell to break away first. This conclusion was strengthened when an Asterias attacked an oyster which had been suffering from a severe attack by Polydora, the shell-boring mudworm. Here the edge of the shell remained unbroken, while one valve was broken across where it had been weakened by the excavation of Polydora in the region of attachment of the adductor muscle.

A chain of Crepidula may be attacked from either end or at some intermediate point in the chain. Once an individual has been detached or the chain parted the diverticula of the stomach are everted around the now exposed body of its prey.

The barnacle is the favourite food of the smaller sizes of Asterias. Elminius modestus, the dominant barnacle in the bottom community, is eaten most frequently, but also Balanus where it and Elminius occur together. The method of feeding appears to depend on the strength of the starfish. The group I starfish usually ate all the barnacles which they were capable of detaching, by sucking the contents through the underside. The larger barnacles were then devoured by sucking the contents through the operculum. The group II starfish could feed on all sizes of barnacles by detaching them, but the smaller barnacles were not usually attacked until the larger ones had been eaten.

Solaster seldom overcomes a complete Asterias at once. An Asterias in captivity is actively pursued by Solaster which attaches itself to one or more arms of the Asterias. An arm is soon autotomized by the Asterias, and devoured by the Solaster (P1. I, fig. I). After digestion, the spicules of Asterias are rejected.

Hyas presents an interesting study in behaviour. When an Asterias is feeding on a mollusc, the Hyas appears to be waiting for scraps, and when the shell 
of the prey is discarded it claws out what few remains the Asterias has left. In many instances, however, the Hyas becomes impatient and attacks the Asterias itself, which it grips between its two chelipeds then proceeding to use its mandibles to chew off the tip of the arm of the Asterias (P1. I, fig. 2). Since the sensitive eye spot is located here such an action must cause serious damage to the starfish, but in many cases it is followed by complete autotomization of the arm, which is then devoured. In some instances the constriction of the arm by the chelipeds of Hyas is so severe that the distal portion of the arm becomes functionless and withers. In one of the specimens in Pl. I, fig. 2, a new arm tip appeared at the point of constriction after several weeks. It is a strange fact that although Hyas frequently attacks and feeds on Asterias it seldom attacks Solaster. This may be coupled with an interesting local tradition that Solaster may be used as bait to poison marauding garden cats, but Asterias is not mentioned in this capacity. It is possible that Hyas can detect some toxic substance in the flesh of Solaster and it was decided to investigate this by simple experiment. Ten small pieces, from each of a freshly dead Asterias and Solaster, were placed in a glass trough with two Hyas. After several hours it was found that all the pieces of Asterias had been consumed, while all ten of the pieces of Solaster remained. After another hour, no further feeding had taken place, and ten more pieces of Asterias were added with the same result. Evidently there is some substance in Solaster which renders it undesirable to Hyas. I have, however, observed one Solaster eat a smaller one of the same species, but it was almost certainly already dead.

\section{RATE OF FEEDING}

Experiments in Canada (Needler, I94I) showed that one starfish may kill three oysters of about half its own length in one week, and much larger numbers of spat. A starfish was found by experiment to require a diameter of about $I_{2}^{\frac{1}{2}}$ times the length of an oyster to attack it successfully. Since most of the starfish on Canadian beds are between 2 and 3 in. in diameter, the greatest danger is to spat or small oysters.

In America Mead (I90I) noticed that a single small Asterias forbesi devoured over 50 clams (Mulinia lateralis) in 6 days. Galtsoff \& Loosanoff (I939) showed in the laboratory, at Milford, Conn., that one medium-sized starfish consumed thirteen I-year-old oysters in 4 days. One small starfish of $\mathrm{I} \cdot 7 \mathrm{~cm}$ diameter destroyed 25 oyster spat of less than $\mathrm{I} \mathrm{cm}$ diameter in 3 days. They found that in experiments conducted in outdoor tanks during the pre-spawning period from May to July, the starfish fed only rarely, but after completion of spawning they became exceedingly voracious until the onset of low temperatures in winter and early spring.

In Exp. I (above) the starfish were confined in indoor tanks protected from the influence of lowest temperatures. Uninterrupted feeding took place from 
the beginning of January to the beginning of February, although temperatures dropped at times to a minimum of $3.0^{\circ} \mathrm{C}$. Feeding ceased completely between 3 and I2 February when minimum temperatures of $2.0^{\circ} \mathrm{C}$. were recorded, and was resumed as temperatures began to rise again. One male Asterias spawned on II May and 2 others on 29 May, but feeding was interrupted only for a few days before and after spawning, although the Asterias were greatly swollen with gonads. In this instance the behaviour of $A$. rubens seems to differ slightly from $A$. forbesi, which is inhibited from feeding by temperatures between 0 and $6^{\circ} \mathrm{C}$. The rate of feeding during the summer months was less than that during the first $4-5$ months of the year. Although an oyster was devoured in less than $24 \mathrm{~h}$, the maximum number eaten by four starfish in one week during the period under observation was eight, representing an average of two per starfish. These oysters were at least 3 years of age and between 44 and $76 \mathrm{~mm}$ average diameter.

Subsequent experiments showed that the smaller sizes of Asterias ate up to 200 barnacles each in one week. Larger starfish ate two to three adult mussels per week, each one usually taking between I5 and $24 \mathrm{~h}$ to open and consume one mussel.

In the feeding experiments an Asterias from group III ate significantly more than a larger starfish from group IV in the same time.

\section{FEEDING AND DistribUtion}

The distribution of Asterias and Solaster in the River Crouch was investigated by a survey on Io May I954. Five-minute dredge hauls were made, using two $4 \mathrm{ft}$. power dredges, throughout the length of the river along a line intermediate between L.W.o.s.T. and mid-river. It is known that the numbers of starfish vary in relation to the distance offshore and the type of bottom, and this arbitrary line was selected as being most likely to reveal the presence of both species. The results have been interpreted graphically (Text-fig. 2). Certain stretches of the river could not be sampled, usually because of the presence of large numbers of boat moorings.

Both Asterias and Solaster were absent from the lower end of the river and this is believed to be due to the presence of accumulations of silt, since both species are found just outside the river, where Asterias in particular is very abundant. The largest numbers of Asterias were found in the neighbourhood of Burnham-on-Crouch, with the greatest concentration at the Southward Laying. The numbers of Asterias fell markedly higher upstream and none were found more than $4 \frac{1}{2}$ miles above Burnham. Solaster, however, was found to be present throughout the river at least as far as 7 miles above Burnham, beyond which no further samples were taken. The largest numbers of Solaster were found higher upstream than the main concentrations of Asterias. It was evident from the results that the largest numbers of Asterias were associated 


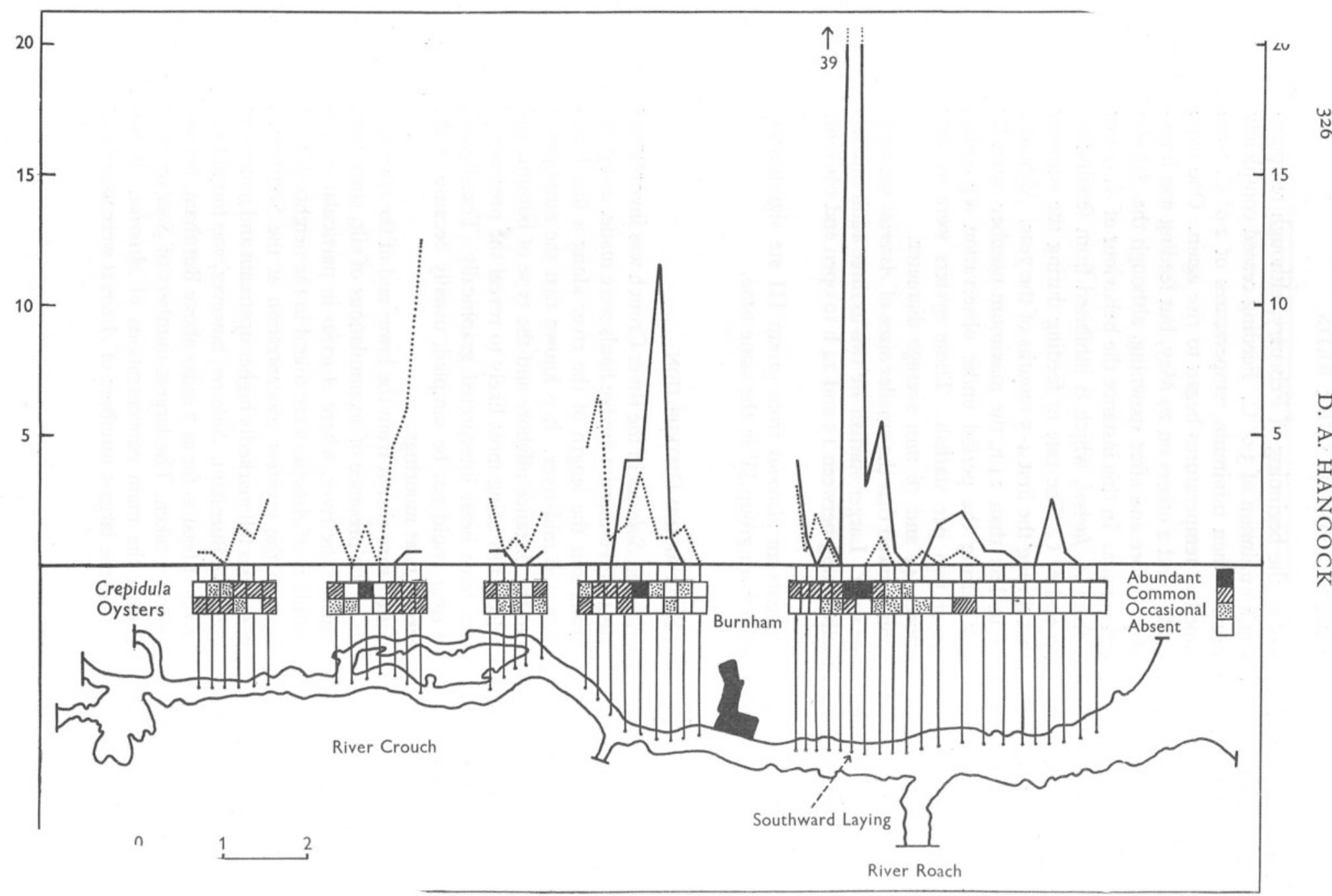

the River Crouch, Essex, and the density of Crepidula and oysters. Solaster; - Asterias. 
with derelict or semi-cultivated oyster ground with a bottom fauna characterized by a high proportion of Crepidula. Asterias, and less frequently Solaster, are sometimes found on the shore above L.W.o.s.T.

A more intensive survey was made of the distribution of starfish over the Southward Laying, where the highest concentration of Asterias was recorded. This is an oyster ground which has the characteristics of both cultivated and uncultivated ground in its different parts. The shore is mainly muddy, and Asterias is only infrequently found above L.W.o.s.T. Previous surveys made using a van Veen grab sampler had shown that the main concentrations of oysters and their spat occur up to $50 \mathrm{~m}$ offshore, largely as a result of intensive cultivation of this area and removal of Crepidula. Further offshore there are proportionately more Crepidula, until by about $75 \mathrm{~m}$ from low-water mark the bottom fauna consists almost entirely of chains of Crepidula. Barnacles are profuse over most of the area, their numbers dropping slightly further offshore. A dredge survey was made of this laying by taking parallel hauls with two oyster dredges at $20 \mathrm{~m}$ intervals. The first haul was made parallel to the shore and $10 \mathrm{~m}$ offshore from L.w.o.s.T. It was found (Text-fig. 3), that the main concentrations of Asterias occur on the offshore part of the ground in a region characterized by a high population of Crepidula. It was from this area that the I0,000 Asterias mentioned previously had been removed in 3 weeks' dredging in March. The River Crouch is $450 \mathrm{~m}$ wide in the Southward Laying region. It can be seen that Asterias occupies the area between L.W.o.s.T. and about I $50 \mathrm{~m}$ offshore. Solaster is more likely to be found in the mid-river part, overlapping the Asterias range only slightly.

\section{Discussion}

Ecologically, the various rivers of Essex provide very similar situations, and Crepidula forms the bulk of the benthic biomass (Knight-Jones, I952). Mistakidis (I95I) found that in the Rivers Crouch and Roach the climax community on uncultivated ground is dominated by Crepidula, and in the River Blackwater by Crepidula, Ascidiella and Ciona. On cultivated well-stocked oyster grounds where Crepidula is present the equilibrium is an artificial one and has to be maintained by frequent dredging and harrowing. On such oyster beds the bottom community in Essex may be described as characterized by Ostrea with Elminius as epifauna. Urosalpinx occurs in varying numbers in the Essex rivers and is well suited by the conditions on cultivated grounds.

It is evident that there are ample quantities of food for starfish in the rivers, where cultivated and uncultivated grounds occur side by side. Although Mytilus is not abundant in the River Crouch, it appears to provide the favourite food of Asterias. Mytilus is usually discouraged on oyster beds because of its habit of binding oysters and shells bearing spat together with byssus threads and because its presence increases the deposit of silt. 
During the laboratory experiments it was noted that when oyster spat was devoured by Asterias the two valves were only rarely detached from each other. At the end of 1953, a survey had been made of the Southward Laying, Essex, using dredges and a van Veen grab sampler. From the results of this survey it was calculated that there had been a total mortality of $73 \%$ of the 1953 settlement of oyster spat before the end of December I953. It was estimated

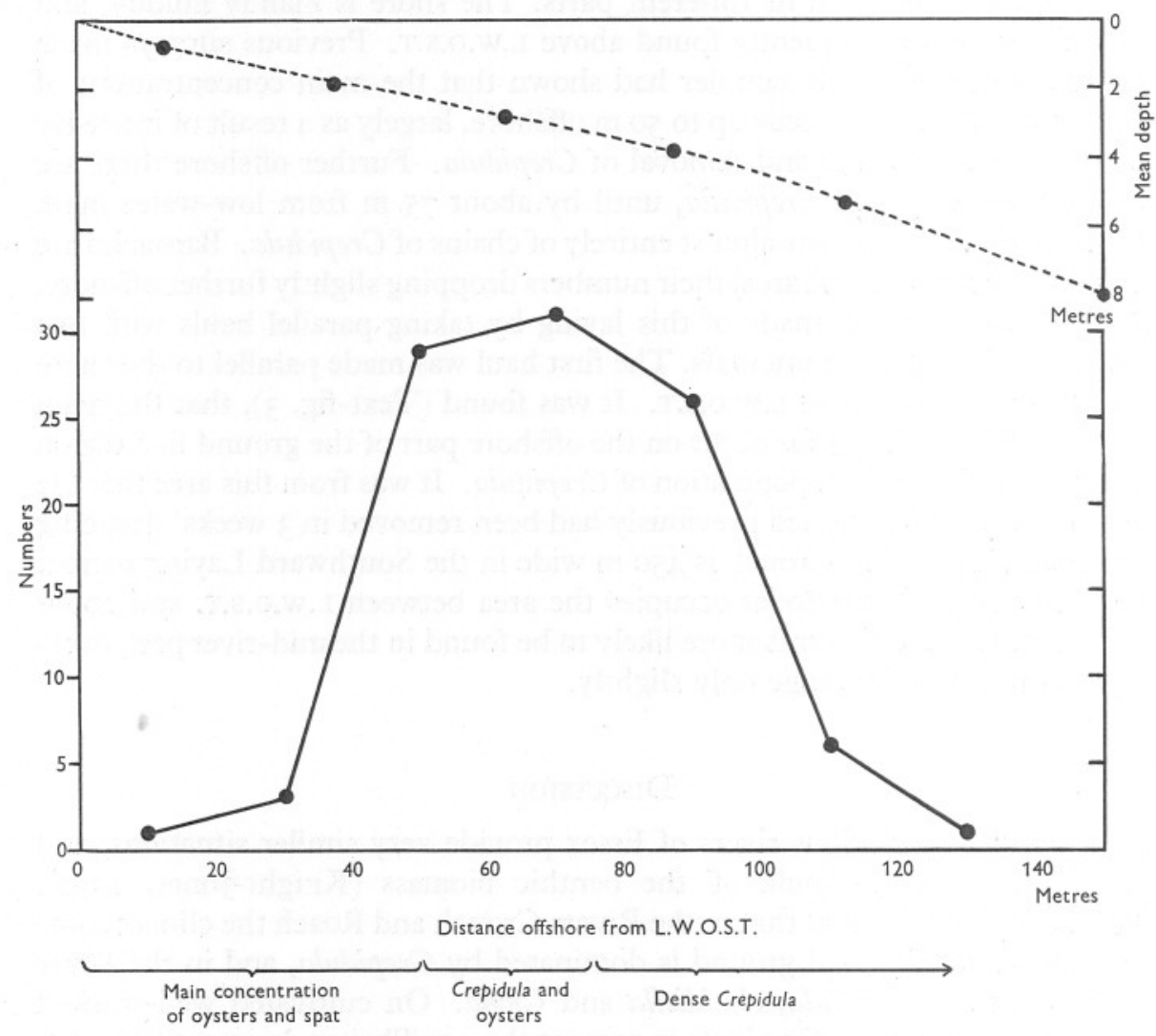

Text-fig. 3. Distribution of Asterias rubens on the Southward Laying, River Crouch.

that $58 \%$ of the spat had been destroyed by Urosalpinx, leaving a mortality of only $15 \%$ attributable to other causes (Hancock, I954). One of these causes is likely to be starfish, although smothering by silt and attacks by Carcinus are considered to be prominent amongst the dangers to which oyster spat are exposed (Knight-Jones, 1952). It can be concluded that Asterias is by no means the most important cause of mortality amongst oyster spat in these rivers, although it may account for some of it.

From the viewpoint of oyster culture, the problem is to what extent Asterias behaves as a predator on oysters and their spat. There is evidence 
from observations in the field that the largest numbers of Asterias are to be found amongst the most dense concentrations of Crepidula. Laboratory experiments have shown that when oysters and Crepidula are present side by side, larger numbers of Crepidula are likely to be consumed. The smaller sizes of Asterias show a marked preference for barnacles over oyster spat. Crepidula and barnacles occur in enormous numbers in the River Crouch and compete with the oyster and its spat for space and food supply. Asterias often feeds on Urosalpinx, which has been shown to eat large numbers of oyster spat. It would not be possible to estimate the negative value of pests eaten by starfish in terms of oysters, but Asterias has been found to feed significantly more on animals which are important predators and competitors than on the oysters themselves. The figures from the feeding experiments show that Asterias must play a large part in reducing their numbers. They also show, however, that the larger starfish can and will eat many oysters in the absence of other food. In Essex, oyster grounds are seldom free from large numbers of barnacles or remote from quantities of Crepidula. It must be concluded that Asterias provides some measure of control of the pests of oyster grounds and as such can be regarded as beneficial to oyster culture. There is no doubt that a certain number of oysters and spat fall prey to Asterias, but it is felt that severe damage is only likely to occur when starfish are present on highly cultivated grounds with large concentrations of oysters and their spat. In such circumstances, removal and destruction of the starfish is recommended. When, however, a derelict ground is being cleaned by dredging and any Asterias taken can only be feeding on Crepidula and barnacles, to destroy the starfish would be a misguided policy. Starfish are known to be capable of migrating, but there has been no evidence that under the conditions in these rivers a cultivated ground provides a greater attraction than an uncultivated one. It is possible that under controlled conditions starfish could be transplanted to the more isolated of the derelict grounds and used as a means of reducing the numbers of pests. Before relaying oysters to such a ground, chemical control to remove the starfish might have some application, but it is felt not to be justified under normal conditions.

Solaster and Hyas have been found to be natural enemies of Asterias and must have some effect in limiting the size of its population. The two species of starfish differ slightly in distribution, and this fact may lessen the effects of feeding by Solaster on Asterias.

\section{SUMMARY}

Laboratory and field observations were made on the food and feeding of the starfish in relation to its role as a predator on oyster beds in the rivers of Essex, particularly in the river Crouch.

Asterias rubens was found most likely to be associated with large numbers of Crepidula, the most serious competitor of the oyster. 
Laboratory experiments showed that although Asterias occasionally ate spat and adult oysters, the greater part of its food was made up of organisms which are competitors of the oyster. The smaller sizes of Asterias ate large numbers of barnacles, with occasional spat of oysters and Crepidula. The larger occasionally ate oysters and oyster spat, but almost always exhibited a preference for mussels and, in the absence of these, for Crepidula, and sometimes even for Urosalpinx.

Some observations were made on the method and rate of feeding and distribution of Asterias and Solaster papposus, and certain aspects of the feeding behaviour of the stone crab, Hyas araneus.

It was concluded that Asterias is not such a serious enemy of the oyster as was previously supposed, and that under certain conditions, its presence may be beneficial to oyster culture.

\section{REFERENCES}

Blegvad, H., I9r4. Food and conditions of nourishment among the communities of invertebrate animals found on or in the sea-bottom in Danish waters. Rep. Danish Biol. Sta., No. 22, pp. 4I-78.

Bull, H. O., I934. Aquarium observations on the rate of growth and enemies of the Common Star-Fish, Asterias rubens L. Rep. Dove Mar. Lab., Ser. 3, No. 2, pp. 60-3.

CAHN, A. R., I950. Oyster culture in Japan. Fish. Leafl., Wash., No. 383, pp. I-80.

Collard, A. P., I902. The Oyster and Dredgers of Whitstable, 9I pp. London: Joseph Collard.

Cú́not, L., I887. Contribution à l'étude anatomique des Astérides. Arch. Zool. exp. gén., T. 2, No. 5 .

Forbes, E., I84I. A History of British Starfishes, 267 pp. London: John van Voorst.

GALtSOFF, P. S. \& LoosanofF, V. L., I939. Natural history and method of controlling the starfish (Asterias forbesi, Desor). Bull. U.S. Bur. Fish., Vol. 49, pp. 75-132.

HANCOCK, D. A., I954. The destruction of oyster spat by Urosalpinx cinerea (Say) on Essex oyster beds. F. Cons. int. Explor. Mer, Vol. 20, pp. I86-96.

HunT, O. D., I925. The food of the bottom fauna of the Plymouth fishing grounds. F. Mar. biol. Ass. U.K., Vol. I3, pp. 560-98.

InvING, L., I924. Ciliary currents in starfish. F. exp. Zool., Vol. 4I, pp. II 5-24.

KNIGHT-JoNES, E. W., I952. Reproduction of oysters in the Rivers Crouch and Roach. Fish. Invest., Lond., Ser. 2., Vol. I8, No. 2, pp. I-48.

Korringa, P., I95I. The shell of Ostrea edulis as a habitat. Arch. néerl. Zool., Vol. Io, pp. 32-152.

LAMBERT, L., I95I. L'ostreiculture et la mytiliculture en Zélande (Pays-Bas). Rev. Trav. off. Pêches marit., T. I6, pp. III-28.

LAver, H., I9I6. The Colchester Oyster Fishery, 92 pp. Colchester: Colne Fishery Board.

LeE, C. F., I951. Technological studies of the starfish. Fish. Leafl., Wash., No. 39I, pp. I-4I.

Loosanoff, V. L. \& ENGle, J. B., I942. Use of lime in controlling starfish. Res. Rep. U.S. Fish. Serv., No. 2, pp. I-29.

Mead, A. D., rgor. The natural history of the starfish. Bull. U.S. Fish. Comm., Vol. I9, pp. 203-24. 


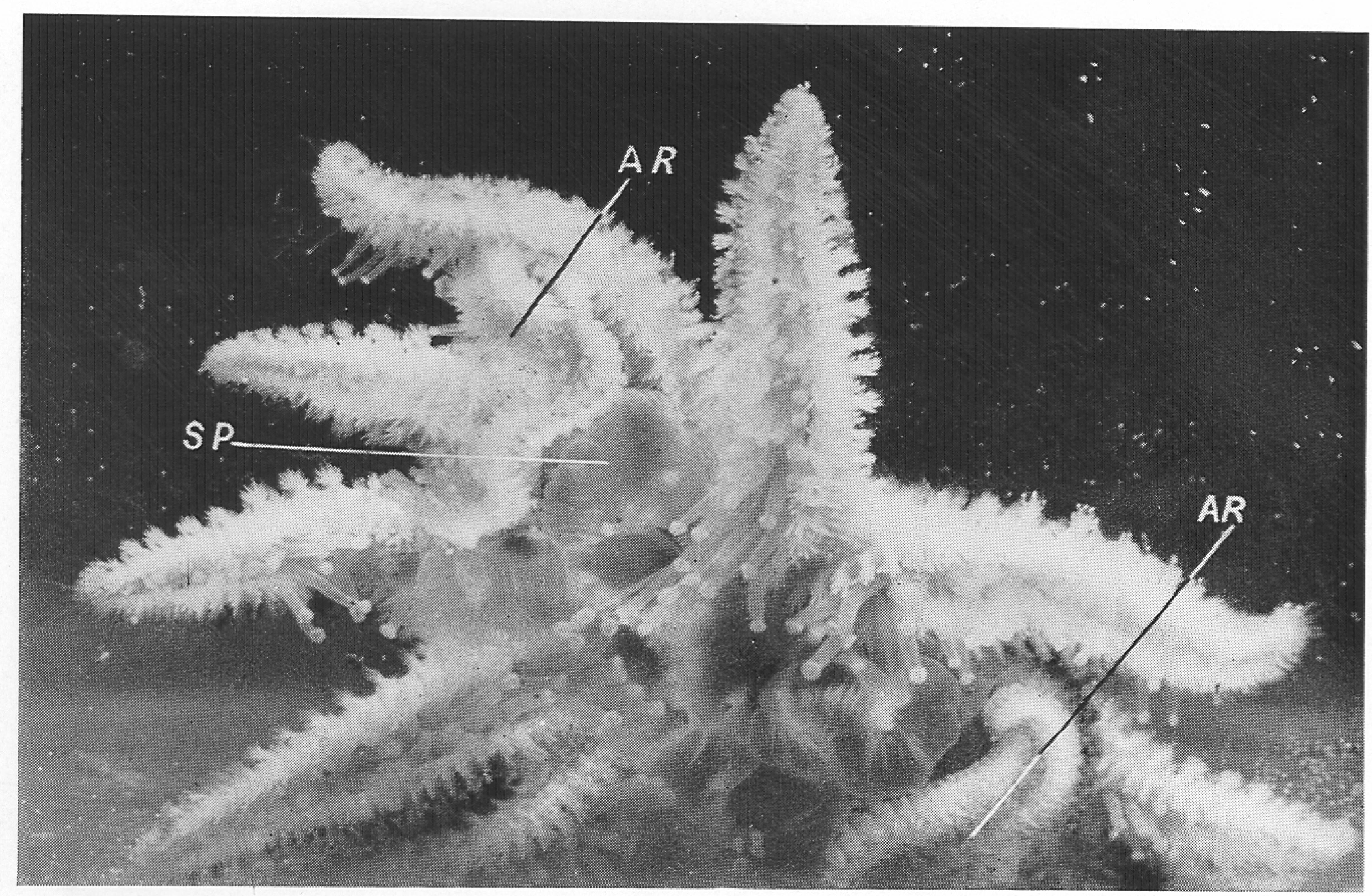

Fig. I

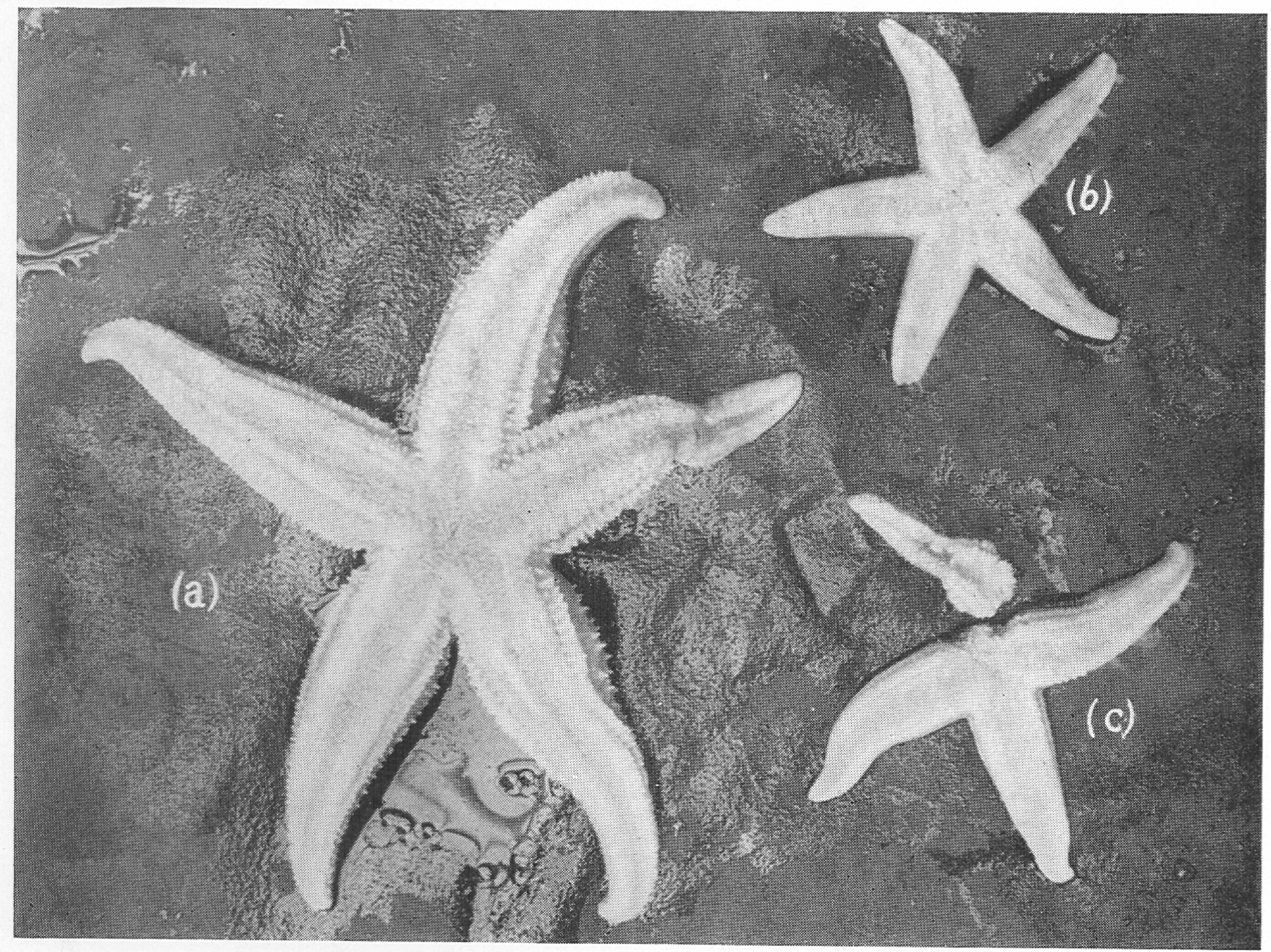

Fig. 2

(Facing p. 330) 
Mistakidis, M. N., I95I. Quantitative studies of the bottom fauna of Essex Oyster Grounds. Fish. Invest., Lond., Ser. 2., Vol. I7, No. 6, pp. I-48.

Mortensen, Th., I927. Handbook of the Echinoderms of the British Isles. Oxford University Press.

Needler, A. W. H., I94I. Oyster farming in Eastern Canada. Bull. Fish. Res. Bd Can. No. 60 , pp. I-83.

Sawano, Eisiro \& Kinji Mitsugi, I932. Toxic action of the stomach extracts of the starfishes on the heart of the oyster. Sci. Rep. Tôhoku Univ., Ser. 4, Vol. 7, No. I, pp. $79-88$.

SchiemenZ, P., 1895. How do starfish open oysters? F. Mar. biol. Ass. U.K., Vol. 4, pp. 266-85.

VAN DER HEYDE, H. C., I922. On the physiology of digestion, respiration and excretion in echinoderms. Academic Thesis, Amsterdam, I20 pp.

Vevers, H. G., I949. The biology of Asterias rubens, L.: growth and reproduction. f. Mar. biol. Ass. U.K., Vol. 28, pp. 165-87.

\section{EXPLANATION OF PLATE I}

Fig. I. Solaster papposus attacking Asterias rubens, which has autotomized an arm. AR., arms of Asterias; SP., everted stomach pouches of Solaster. Photo: P. J. Warren.

Fig. 2. Asterias rubens attacked by Hyas araneus, showing (a) constriction of one arm, (b) removal of three arm tips, and (c) autotomization of two arms. Photo: D. Key. 